\title{
Benefits Of Inmate Employment Programs: Evidence From The Prison Industry Enhancement Certification Program
}

Jeffrey D. Hopper, Transylvania University, USA

\begin{abstract}
The United States is experiencing a persistent increase in its prison population and, consequently, a steady increase in public spending on incarceration. A possible systemic change to mitigate these trends is a return to historically cost effective inmate labor programs. Government savings and business revenues from these programs have been documented. Additional benefits have been hypothesized from an associated reduction in recidivism. This paper examines if this recidivism effect occurs following inmate participation in the Prison Industry Enhancement Certification Program (PIECP). Inmate characteristics and PIECP participation variables are identified as potential predictors of recidivism. Logit regression procedures, including a two-stage instrumental variable procedure to address endogeneity, are used to capture the predictive value of the independent variables and quantify the reduction in the odds of inmate recidivism attributable to PIECP participation. The results indicate that employment in a PIECP program contributes to a statistically significant reduction in the odds of inmate recidivism.
\end{abstract}

Keywords: Prison Employment; Recidivism; PIECP; Inmate Work Program

\section{INTRODUCTION}

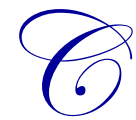

rime is a major societal problem in the United States that creates a significant drain on public and private resources. The long-term trend in the United States is that of an increasing number of prisoners in federal, state and local institutions. The average annual growth rate of the prison population in the mid-1980s through the early 2000s was around $6.0 \%$. The more recent levels still indicate annual growth of around 3\% (U.S. Department of Justice [DOJ], 2012b). In 2011 the U.S. prison population exceeded 2.23 million, which means that approximately 1 in every 107 adults was incarcerated in a local, state, or federal facility (DOJ, 2012a). Currently, with only $5 \%$ of the world's total population, the U.S. holds $25 \%$ of the world's prison population (Liptak, 2008). As a result, according to the International Centre for Prison Studies (2009), the United States has the highest per capita incarceration rate, 756 of 100,000, of any country in the world and 7 to 10 times that of most other democracies. ${ }^{1}$

The obvious economic problem is that increasing prison populations have required rapidly escalating expenditures on incarceration. According to the U.S. Department of Justice's Bureau of Justice Statistics (2012b), state budget expenditures on incarceration have increased, in 2001 constant dollars, from $\$ 15.0$ billion in 1982 to $\$ 53.5$ billion in 2010. This is approximately $\$ 170$ per U.S. resident, up from $\$ 65$ per resident in 1986 . The Department of Justice reports that, in 2010, the average annual incarceration cost per state inmate was $\$ 28,323$ and the average annual cost of incarceration per federal inmate was $\$ 28,284$.

Further, contributing to this problem is post-release recidivism, where former inmates return to crime and are rearrested and potentially reincarcerated. Recidivism studies from the U.S. Department of Justice's Bureau of Justice Statistics $(1998,2002)$ examining offenders released from prisons in 1983 and 1994 found high rates of

\footnotetext{
${ }^{1}$ Comparatively, the rate for England is 152 per 100,000, for France 96 per 100,000 and for Japan 63 per 100,000.
} 
recidivism among released prisoners. Of the 108,580 prisoners released from prisons in 11 states in 1983, nearly $63 \%$ were re-arrested within a three-year period, $47 \%$ were convicted of a new crime, and $41 \%$ were returned to prison or jail. Examining nearly 300,000 prisoners released in 15 states in 1994, 68\% were rearrested within three years, $47 \%$ were convicted of a new crime, and 25 percent were recommitted to prison with a new sentence. More recent studies confirm the high rearrest rates and show reincarceration estimates in the three-year period post-release that are in line with the previous studies documenting the reincarceration rate in the $43.3 \%$ to $45.4 \%$ range (Pew Center, 2011).

These recidivism occurrences are an important concern as they perpetuate the aforementioned problems and they serve as the primary focus of this paper. Economic theories on crime and punishment, as well as human capital, extend to suggest that providing inmates with employment opportunities may reduce recidivism rates, either by increasing the opportunity cost of crime or by providing marketable skills that can be used in place of criminal activity (Becker, 1968; Lochner, 2004). Steven Levitt (1999) proposes that "if working a prison job has even a relatively small impact on recidivism, the social benefits could be enormous." He continues, "for instance, if working a prison job resulted in $10 \%$ of prisoners dropping out of crime upon their release, then the annual social benefit from reduced crime would be $\$ 6.1$ billion." The theorized potential for vocational training while incarcerated to reduce recidivism is not new. It served as one of the primary arguments in 1979 when the Percy Amendment to the Justice Improvement Act created the Prison Industry Enhancement Certification Program (PIECP) which allows private industries to employ inmates while incarcerated. The program was expanded by Congress in 1984 and again in 1990 to potentially cover all 50 states. During the past twenty years, many states have enacted laws permitting the use of convict labor by private enterprises and 38 states have initiated participation in the PIECP.

\section{Benefits of the PIECP}

The PIECP involves private organizations and the federal and state governments working cooperatively in prison-based joint ventures. The program provides private industries access to the growing prison population and the government access to private industry's revenues. The program faced initial criticism with questions about the overall effects of it on the nation's GDP, society as a whole, and the low-skilled portion of the U.S. labor force's wages. Since the demographic profile of prisoners in terms of age, gender, education, and race of the typical prisoner is similar to the typical low-skilled portion of the U.S. labor force, some were concerned that these programs may cannibalize some of those low-skilled jobs. Supporters argued that these jobs would otherwise have been moved offshore. Consequently, several conditions must be met in the participating firm's application process the sale of inmate-made products in the open market; certification that equivalent wages to private employment in a similar labor market with comparable benefits are provided; certification that there is no private sector worker displacement - a condition of voluntary participation in accordance with EEOC hiring guidelines; consultation with organized labor and local private industry; and compliance with environmental policy (DOJ, 2004).

In its current state, the program exists to encourage states and units of local government to establish employment opportunities for inmates that approximate private-sector work opportunities, and the program is designed to place inmates in a realistic work environment, pay them the prevailing local wage for similar work, and enable them to acquire marketable skills to increase their potential for successful rehabilitation and meaningful employment upon release. The U.S. Department of Justice (2004) states two primary objectives of this program: (1) inmate production that contributes to society, offsets incarceration costs, compensates crime victims and supports inmate families, and (2) success in the community once the inmate is released.

The success of the program in meeting the first objective is well documented in financial terms as the National Correctional Industries Association (NCIA) publishes quarterly cumulative accounting data for the PIECP. From the program's inception in 1979 through the $3^{\text {rd }}$ quarter of 2012, there have been 45 certifications granted and those programs have provided over $\$ 626.8$ million in gross wages to inmates. From those wages, over $\$ 368.2$ million was withheld in deductions with $16.8 \%$ of that going to victims programs, $51.3 \%$ to room and board, $10.6 \%$ to family support, and $21.3 \%$ to taxes. Of the $\$ 258.7$ million in net wages, $13.25 \%$ was placed into mandatory savings accounts for post-release use (NCIA, 2012). Thus, even without a reduction in recidivism, the program effectively reduces the cost of incarnation, offers some level of financial restitution to victims, and provides some family support. 
The second objective - success in the community once the inmate is released - could provide further benefits to the government from a reduction in future expenditures on enforcement, prosecution, incarceration, and the tax benefits of a gainfully employed citizen. However, success in the community once the inmate is released is more difficult to measure. Considerable research in this area focuses on post-release employment as a proxy for success, with the assumption that if the ex-convict is gainfully employed, there will be no reason to engage in criminal behavior (Weiman, 2007). Alternatively, one of the most direct measures of success available is recidivism. The impact of PIECP participation on inmate recidivism rates represents a void in the existing literature as this has not been fully explored or definitively established (Petersik, 2003). Some programs have not been evaluated at all and, for those that have, the studies have not sufficiently done so. Thus, while some efforts have been made, this paper adds additional information to the recidivism assessment question and offers improved methodology with the addition of controls for self-selection biases.

\section{DATA}

The data used in this study were obtained from the Indiana and Tennessee Departments of Corrections (DOC). The Indiana DOC maintains information about prisoners through their Offender Information System database. The data from Indiana's DOC were merged with data from the Prison Enterprises Network, the Indiana DOC's labor division that operates the state's PIECP. These sets were merged using the DOC's unique prisoner identification numbers, resulting in 44,286 non-intraprison release events. The identification numbers provide an anonymous common reference for data management. The Tennessee Offender Management Information System is the comprehensive data system in which the Tennessee DOC manages information about persons who have been, or currently are, under the Department's jurisdiction. These data were merged with data from the Tennessee Rehabilitative Initiative in Correction, which operates the Tennessee PIECP by prisoner identification number, resulting in 33,129 non-intraprison release events. A larger pooled sample, that combines the Indiana and Tennessee data, is also used.

The data sets provide information on inmates with a release event between 1998 and 2008. This period captures some stability in post-release employment conditions as it is prior to the most recent U.S. recession. The information on the prisoners contains demographic characteristics and incarceration history, including age, gender, race, education level, marital status, offense type, prior offense, time served, maximum sentence, facility of incarceration, all incarceration dates, all release dates, and information on PIECP participation. The summary statistics for these variables are in line with national averages for prisoners. The measures for recidivism created are dummy variables codifying a reincarceration event within one year, two years, or three years from prior release.

An adjustment to the PIECP participant variable was necessary so that it only includes inmates who have at least six months of employment in a PIECP job. As the effects of participation are theorized to be attributable to the training effects in human capital theory, the inmates must have adequate time for the training to occur. If an inmate had been employed for one day and was terminated, then no training effects would be expected and therefore, this individual should not be considered a participant. The resulting inmate PIECP participation level is slightly under $2 \%$ in both data sets. Also, working inmate subsets of the full data sets were created. The observations in these sets are limited to inmates who held jobs - PIECP or traditional - while incarcerated.

\section{METHODOLOGY}

The dependent variable of interest in this study, a recidivism event, is binary and thus suited for a logistic regression model. To examine the effect of PIECP participation, a logit model is specified with independent variables for age, gender, education, race, marital status, offense type, prior recidivism, security level, length of sentence, participation, and an age and participation interaction term. Variations of the model, discussed below, include a logit model with an instrument for the participation variable based on the availability of a PIECP facility and a two-stage instrumental variable (IV) model where a proxy for participation is created and used in the model. Each model is used to examine the Indiana, Tennessee, and pooled sample data. The models are specified for a oneyear, then two-year, and also a three-year period post-release reincarceration event as a marker of recidivism. This is all repeated to compare a working inmate's sample, which excludes inmates who were not employed in any type of prison work program, to the PIECP participant sample. 
With any regression analysis, there is a concern about factors that may bias the results and lead to erroneous conclusions. A primary concern, when using observational data to examine the effects of a treatment (as is the case in this study), is that there is endogeneity. As described by Lee (2005), "in observational data, treatment is self-selected by the subjects, which can result in selection problems - 'selection-on-observables' and 'selectionon-unobservables'." Thus, the first concern is to ensure the inmates included in the regression analysis have similar 'observable' characteristics or that the individuals in the treatment and comparison groups are closely matched. The second concern regarding endogeneity results from omitted or 'unobserved' individual characteristics.

The observable - or overt - bias can be addressed by matching the non-participating population characteristics to those of the participation population. One technique is to match based on a propensity score. However, it was not necessary in this case as a simple observational matching correction appears to be sufficient. ${ }^{2}$ A subset of the matched control group consisting of working inmates is also examined. This group is used to examine the independent variables' effect on recidivism for only the working inmates - those employed in any work program while incarcerated.

The second endogeneity issue - the unobservable concern - is omitted variable bias. The most direct solution would be to include the omitted variable into the regression. However, since the omitted characteristic of concern may be something such as motivation, need to work, or ability, it may not be possible to include. Thus, the bias is not simply because the inmate's ability was left out of the regression. The bias manifests when the variable affecting recidivism is correlated with both the participation event and recidivism. Arguably, those with higher ability are more likely to work. Thus, the coefficient showing the effects of participation may actually be showing the effects of ability. To correct this problem, a proxy for participation can be used. To be a useful instrument - and therefore remove the endogeneity - the proxy must not itself belong in the explanatory equation and must be correlated with participation (so that those effects remain), but not be correlated with the unmeasured characteristic affecting recidivism (so that those effects are in the error term).

The identified instrument is the availability of a PIECP program in the correctional facility. The suitability of the instrument is examined by determining whether the variable is correlated with participation, but not correlated with recidivism independently of participation. This instrument is definitely correlated with participation as there must be a facility in the prison in order for the prisoner to participate. On the surface, the second criterion seems to hold as the location should not be related recidivism independently of PIECP participation. However, if those inmates with higher abilities are being systematically sent to prisons with PIECP programs, then there would be a correlation between these items. Conversely, if the inmate's facility assignment is random, then there should be no correlation and the second criterion will be satisfied. According to the Indiana and Tennessee DOC's $(2012,2011)$, the primary consideration for facility assignment is the inmate's security designation. After that, assignment decisions are based on capacity. As most facilities are operating at, or near, maximum capacity, inmates are assigned or transferred to facilities based on available beds. ${ }^{3}$ Thus, it is reasonable to assert that criteria for a suitable instrument are satisfied.

The instrument - PIECP facility location availability - is used in two different models. The first use of the PIECP facility location instrument is as an independent variable in a logit regression. The primary difference in the logit with facility instrument specification and the primary logit specification is the use of the PIECP facility availability variable as an instrument in place of the potentially biased PIECP participation variable. After this, a two-stage instrumental variable (IV) model is used where the factors predicting participation, including facility location, are regressed in the first stage. The second stage uses recidivism as the dependent variable and the predicted values from the first stage are used to instrument the participation variable.

\footnotetext{
2 The data was first matched by the inmate's security level designation. Thus, only inmates who could have been assigned to a location with a PIECP facility are examined as there are no programs operating in category one (minimum security) or category five (maximum) security) prisons. The next adjustment was for age outliers to allow time to develop human capital and time to use it upon release. These adjustments removed the observed differences between PIECP and non-PIECP participants potential for participation, age, sentence length and education. T-tests confirm no statistically significant differences in the groups.

${ }^{3}$ To confirm this random assignment assumption the mean characteristics of all inmates in PIECP facility locations are tested against all inmates in non-PIECP facilities of the same security designation. The conclusion is that any differences in the mean values between facilities would likely be due to chance.
} 


\section{RESULTS}

The full regression results from all specifications are in line with the expectations from human capital theory and economic theories of crime. The variables expected to be predictive of recidivism, such as age, education, type of crime, sentence length, and previous recidivism events, are consistently found to be statistically significant across the various models and release periods, and all of the full models' likelihood ratio's chi-squares are all found to be high enough to reject the hypothesis that all the coefficients are equal to zero.

However, for this paper, the effect of PIECP program participation on recidivism is of primary concern. Thus, from each of the 54 regression specifications (three models in three time periods, for all inmates and working inmates, for Indiana, Tennessee, and a pooled sample), the participation variable's coefficient is isolated from the full results and examined below. Presented in the following tables are the coefficients for the PIECP participation variable or instrument, $\mathrm{p}$-values from the Wald Chi-Squared tests, standard errors, and odds ratios from the logit, logit with facility instrument, and the two-stage IV specifications each examining a one-year, two-year, and threeyear post release period for the full sample and working inmate sample. The sign of coefficient indicates whether participation increases or decreases the odds of recidivism. The size of the effect is illustrated in the odds ratio which is derived through the exponentiation of the participation coefficient where the ratio of the calculated odds shows how much greater (odds ratio greater than 1) or less (odds ratio less than 1) are the odds that the participant is to recidivate relative to a non-participant.

Table 1 shows results from the all inmates Indiana data set in a logit, logit with facility instrument, and a two-stage IV specification for a one-year, two-year, and three-year post release period. The PIECP participation and participation instrument coefficients are negative and consistently significant. As discussed previously, the magnitude of the effects cannot be seen in the coefficient, but the odds ratio captures the size of the effect. The oneyear post release time period results suggest a decrease in recidivism by a factor in the range of 0.792 to 0.899 . The two-year recidivism period coefficients for the full sample are similar to the one-year results in their signs and significance and indicate a reduction factor in the 0.851 to 0.923 range. The three-year time frame is the most scrutinized in the recidivism literature. For this period, Table 1 illustrates that the facility availability participation instrument is not a significant variable in the logit with facility specification. The significant variables form the logit and the IV specifications indicate a recidivism reduction factor for this time period in the 0.881 to 0.928 range.

Table 1: Effects of PIECP Participation on Recidivism, All Inmates (Indiana)

\begin{tabular}{|l|l|l|l|l|l|l|l|l|l|}
\hline & \multicolumn{3}{|c|}{ Logit } & \multicolumn{2}{|c|}{ Logit with Facility Instrument } & \multicolumn{3}{c|}{ IV } \\
\hline All Inmates & Coefficient & (SE) & $\begin{array}{l}\text { Odds } \\
\text { Ratio }\end{array}$ & Coefficient & (SE) & $\begin{array}{l}\text { Odds } \\
\text { Ratio }\end{array}$ & Coefficient & (SE) & $\begin{array}{l}\text { Odds } \\
\text { Ratio }\end{array}$ \\
\hline $\begin{array}{l}\text { PIECP Participation } \\
\text { on One-Year } \\
\text { Recidivism }\end{array}$ & $-0.233 * * *$ & $(0.0124)$ & 0.792 & $-0.107 *$ & $(0.0536)$ & 0.899 & $-0.162 * * *$ & $(0.0254)$ & 0.850 \\
\hline $\begin{array}{l}\text { PIECP Participation } \\
\text { on Two-Year } \\
\text { Recidivism }\end{array}$ & $-0.161 * * *$ & $(0.0161)$ & 0.851 & $-0.075^{*}$ & $(0.0385)$ & 0.923 & $-0.104 * * *$ & $(0.0213)$ & 0.901 \\
\hline $\begin{array}{l}\text { PIECP Participation } \\
\text { on Three-Year } \\
\text { Recidivism }\end{array}$ & $-0.127 * * *$ & $(0.0098)$ & 0.881 & -0.052 & $(0.0272)$ & 0.949 & $-0.074 * * *$ & $(0.0117)$ & 0.928 \\
\hline
\end{tabular}

Note: 28,732 observations. Standard errors in parentheses. $* * * \mathrm{p}<0.01 ; * * \mathrm{p}<0.05 ;{ }^{*} \mathrm{p}<0.10$.

The two-stage IV specification, as discussed before, is included due to concern that some unmeasured characteristics are being captured in the logit coefficients. Hausman tests between the primary logit and the IV estimate can indicate, or potentially rule out, endogeneity. Here, Hausman tests are conducted between the logit and two-stage IV coefficients in the three recidivism periods. The null hypothesis for each test is that the difference between the coefficients is equal to zero. In all cases, the F-statistics are large enough (p-values <.001) to reject the null hypothesis. The conclusion is that there are statistically significant differences in the results of the logit and IV models. Specifically, these results suggest that an unmeasured or omitted variable may have a significant effect on the consistency of the logit estimator, and thus the two-stage IV estimator is the most reliable estimate of the effects of participation on recidivism. 
Table 2 examines only Indiana inmates who are employed, in any capacity, while incarcerated. The Indiana working inmates sample coefficients are consistent with the full sample, but the working sample results show a smaller effect of inmate participation on the odds of one-year recidivism than the full sample results. This is not inconsistent with the idea that there may be some unmeasured motivation to work in the employed inmates. The one-year recidivism period shows a range of odds ratios from 0.832 to 0.924 . However, Hausman tests confirm the working inmates IV specification as the most reliable indicator. In the IV specification, the odds of recidivism are multiplied by a factor 0.864 , indicating there is a $13.6 \%$ reduction in the odds of recidivism for PIECP participants in the year following their release. The three-year coefficients for the working inmates sample also confirm a significant decrease in participant recidivism with an odds factor for the IV model of 0.935, illustrating a $6.4 \%$ reduction in the recidivism odds for participants.

Table 2: Effects of PIECP Participation on Recidivism, Working Inmates (Indiana)

\begin{tabular}{|c|c|c|c|c|c|c|c|c|c|}
\hline \multirow[b]{2}{*}{ All Inmates } & \multicolumn{3}{|c|}{ Logit } & \multicolumn{3}{|c|}{ Logit with Facility Instrument } & \multicolumn{3}{|c|}{ IV } \\
\hline & Coefficient & (SE) & $\begin{array}{l}\text { Odds } \\
\text { Ratio }\end{array}$ & Coefficient & (SE) & $\begin{array}{l}\text { Odds } \\
\text { Ratio }\end{array}$ & Coefficient & (SE) & $\begin{array}{l}\text { Odds } \\
\text { Ratio }\end{array}$ \\
\hline $\begin{array}{l}\text { PIECP Participation } \\
\text { on One-Year } \\
\text { Recidivism }\end{array}$ & $-0.184 * * *$ & $(0.0629)$ & 0.832 & $-0.079 *$ & $(0.0432)$ & 0.924 & $-0.146 * * *$ & $(0.0327)$ & 0.864 \\
\hline $\begin{array}{l}\text { PIECP Participation } \\
\text { on Two-Year } \\
\text { Recidivism }\end{array}$ & $-0.143 * * *$ & $(0.0461)$ & 0.867 & $-0.055^{*}$ & $(0.0303)$ & 0.946 & $-0.094 * * *$ & $(0.0194)$ & 0.910 \\
\hline $\begin{array}{l}\text { PIECP Participation } \\
\text { on Three-Year } \\
\text { Recidivism }\end{array}$ & $-0.116 * * *$ & $(0.0376)$ & 0.890 & -0.043 & $(0.0284)$ & 0.958 & $-0.067 * * *$ & $(0.0272)$ & 0.935 \\
\hline
\end{tabular}

Note: 7,741 observations. Standard errors in parentheses. $* * * p<0.01 ; * * p<0.05 ; * \mathrm{p}<0.10$.

The 'all inmates Tennessee' results in Table 3 appear to be similar to the Indiana results. The one-year Tennessee all inmates PIECP participation coefficients are all negative and significant with odds ratio factors ranging from 0.779 to 0.873 . Again, Hausman tests are conducted between the logit and IV coefficients in the three recidivism periods and the results confirm the preference for the IV specification in all three time periods. The twoyear recidivism period odds ratio illustrates a change in the odds of recidivism by a factor of 0.868 for the IV specification. In the three-year post release period, the IV odds ratio indicates an $11.1 \%$ reduction in the recidivism odds for PIECP participants.

Table 3: Effects of PIECP Participation on Recidivism, All Inmates (Tennessee)

\begin{tabular}{|c|c|c|c|c|c|c|c|c|c|}
\hline & \multicolumn{3}{|c|}{ Logit } & \multicolumn{3}{|c|}{ Logit with Facility Instrument } & \multicolumn{3}{|c|}{ IV } \\
\hline All Inmates & Coefficient & (SE) & $\begin{array}{l}\text { Odds } \\
\text { Ratio }\end{array}$ & Coefficient & (SE) & $\begin{array}{l}\text { Odds } \\
\text { Ratio }\end{array}$ & Coefficient & (SE) & $\begin{array}{l}\text { Odds } \\
\text { Ratio }\end{array}$ \\
\hline $\begin{array}{l}\text { PIECP Participation } \\
\text { on One-Year } \\
\text { Recidivism }\end{array}$ & $-0.249 * * *$ & $(0.0368)$ & 0.779 & $-0.136^{*}$ & $(0.0641)$ & 0.873 & $-0.196 * * *$ & $(0.0497)$ & 0.822 \\
\hline $\begin{array}{l}\text { PIECP Participation } \\
\text { on Two-Year } \\
\text { Recidivism }\end{array}$ & $-0.185 * * *$ & $(0.0581)$ & 0.831 & $-0.101 *$ & $(0.0522)$ & 0.904 & $-0.139 * * *$ & $(0.0382)$ & 0.870 \\
\hline $\begin{array}{l}\text { PIECP Participation } \\
\text { on Three-Year } \\
\text { Recidivism }\end{array}$ & $-0.171 * * *$ & $(0.0496)$ & 0.843 & -0.088 & $(0.0426)$ & 0.916 & $-0.118 * * *$ & $(0.0404)$ & 0.889 \\
\hline
\end{tabular}

Note: 21,836 observations. Standard errors in parentheses. $* * * p<0.01 ;{ }^{*} * \mathrm{p}<0.05 ;{ }^{*} \mathrm{p}<0.10$.

Table 4 examines only inmates in the Tennessee working inmates sample. The results for the participation variables are again consistent with the Indiana specification and the logit and IV specifications continue to suggest that inmate participation in a PIECP program significantly reduces the odds of the participant's recidivism, even relative to other working inmates. With the Hausman tests confirming preference, the one-year period IV model odds ratio indicates a potential $13.8 \%$ reduction in the odds of recidivism, the two-year model indications of $11.3 \%$, and the three-year factor suggests a reduction of $8.9 \%$. 
Table 4: Effects of PIECP Participation on Recidivism, Working Inmates (Tennessee)

\begin{tabular}{|c|c|c|c|c|c|c|c|c|c|}
\hline \multirow[b]{2}{*}{ All Inmates } & \multicolumn{3}{|c|}{ Logit } & \multicolumn{3}{|c|}{ Logit with Facility Instrument } & \multicolumn{3}{|c|}{ IV } \\
\hline & Coefficient & (SE) & $\begin{array}{l}\text { Odds } \\
\text { Ratio }\end{array}$ & Coefficient & (SE) & $\begin{array}{l}\text { Odds } \\
\text { Ratio }\end{array}$ & Coefficient & (SE) & $\begin{array}{l}\text { Odds } \\
\text { Ratio }\end{array}$ \\
\hline $\begin{array}{l}\text { PIECP Participation } \\
\text { on One-Year } \\
\text { Recidivism }\end{array}$ & $-0.228 * * *$ & $(0.0722)$ & 0.796 & $-0.093 *$ & $(0.0472)$ & 0.911 & $-0.149 * * *$ & $(0.0518)$ & 0.862 \\
\hline $\begin{array}{l}\text { PIECP Participation } \\
\text { on Two-Year } \\
\text { Recidivism }\end{array}$ & $-0.179 * * *$ & $(0.0808)$ & 0.836 & -0.076 & $(0.0385)$ & 0.927 & $-0.120 * * *$ & $(0.0609)$ & 0.887 \\
\hline $\begin{array}{l}\text { PIECP Participation } \\
\text { on Three-Year } \\
\text { Recidivism }\end{array}$ & $-0.152 * * *$ & $(0.0623)$ & 0.859 & -0.064 & $(0.0394)$ & 0.938 & $-0.094 * * *$ & $(0.0457)$ & 0.911 \\
\hline
\end{tabular}

Note: 5,951 observations. Standard errors in parentheses. $* * * p<0.01 ; * * p<0.05 ; * \mathrm{p}<0.10$.

In Table 5 the all inmates pooled sample results are examined. Similar to the results from the Indiana and Tennessee models, the logit model with the facility availability substituted for inmate participation does not demonstrate the same magnitude or significance as the logit or the IV specification. Hausman tests again suggest the IV model is the most reliable indicator in the pooled all inmates and also in the working inmates samples. The oneyear IV result suggests a reduction in the odds of recidivism by a factor of 0.834 . The IV specification odds ratio for the two-year recidivism period suggests an adjustment of the odds of recidivism by a factor of 0.890 and that of 0.912 for the three-year period.

Table 5: Effects of PIECP Participation on Recidivism, All Inmates (Pooled Sample)

\begin{tabular}{|l|c|c|c|c|c|c|c|c|c|}
\hline & \multicolumn{3}{|c|}{ Logit } & \multicolumn{2}{|c|}{ Logit with Facility Instrument } & \multicolumn{4}{|c|}{ IV } \\
\hline All Inmates & Coefficient & (SE) & $\begin{array}{l}\text { Odds } \\
\text { Ratio }\end{array}$ & Coefficient & (SE) & $\begin{array}{l}\text { Odds } \\
\text { Ratio }\end{array}$ & Coefficient & (SE) & $\begin{array}{l}\text { Odds } \\
\text { Ratio }\end{array}$ \\
\hline $\begin{array}{l}\text { PIECP Participation } \\
\text { on One-Year } \\
\text { Recidivism }\end{array}$ & $-0.237 * * *$ & $(0.0552)$ & 0.789 & $-0.118^{*}$ & $(0.0694)$ & 0.889 & $-0.181 * * *$ & $(0.0423)$ & 0.834 \\
\hline $\begin{array}{l}\text { PIECP Participation } \\
\text { on Two-Year } \\
\text { Recidivism }\end{array}$ & $-0.174 * * *$ & $(0.0682)$ & 0.840 & $-0.087 *$ & $(0.0468)$ & 0.917 & $-0.116^{* * *}$ & $(0.0579)$ & 0.890 \\
\hline $\begin{array}{l}\text { PIECP Participation } \\
\text { on Three-Year } \\
\text { Recidivism }\end{array}$ & $-0.149 * * *$ & $(0.0510)$ & 0.862 & -0.071 & $(0.0448)$ & 0.931 & $-0.092 * * *$ & $(0.0399)$ & 0.912 \\
\hline
\end{tabular}

Note: 50,568 observations. Standard errors in parentheses. $* * * \mathrm{p}<0.01 ; * *_{\mathrm{p}}<0.05 ;{ }^{*} \mathrm{p}<0.10$.

Table 6 shows the results for the working inmates pooled sample. The coefficients for the participation variables are again negative and significant in the primary logit specification. The more reliable IV specification also consistently indicates that participation in the PIECP program has a significant effect on inmate recidivism across all three post-release periods. In the most informative three-year post-release period, the IV specification's 0.928 odds factor suggests a reduction in the odds of recidivism of $7.2 \%$.

Table 6: Effects of PIECP Participation on Recidivism, Working Inmates (Pooled Sample)

\begin{tabular}{|c|c|c|c|c|c|c|c|c|c|}
\hline & \multicolumn{3}{|c|}{ Logit } & \multicolumn{3}{|c|}{ Logit with Facility Instrument } & \multicolumn{3}{|c|}{ IV } \\
\hline All Inmates & Coefficient & (SE) & $\begin{array}{l}\text { Odds } \\
\text { Ratio } \\
\end{array}$ & Coefficient & (SE) & $\begin{array}{l}\text { Odds } \\
\text { Ratio } \\
\end{array}$ & Coefficient & (SE) & $\begin{array}{l}\text { Odds } \\
\text { Ratio } \\
\end{array}$ \\
\hline $\begin{array}{l}\text { PIECP Participation } \\
\text { on One-Year } \\
\text { Recidivism }\end{array}$ & $-0.206 * * *$ & $(0.1011)$ & 0.814 & $-0.086^{*}$ & $(0.0430)$ & 0.918 & $-0.150 * * *$ & $(0.0320)$ & 0.861 \\
\hline $\begin{array}{l}\text { PIECP Participation } \\
\text { on Two-Year } \\
\text { Recidivism } \\
\end{array}$ & $-0.153 * * *$ & $(0.0773)$ & 0.858 & -0.060 & $(0.0358)$ & 0.942 & $-0.101 * * *$ & $(0.0249)$ & 0.904 \\
\hline $\begin{array}{l}\text { PIECP Participation } \\
\text { on Three-Year } \\
\text { Recidivism } \\
\end{array}$ & $-0.137 * * *$ & $(0.0660)$ & 0.887 & -0.052 & $(0.0341)$ & 0.949 & $-0.075 * * *$ & $(0.0277)$ & 0.928 \\
\hline
\end{tabular}

Note: 13,692 observations. Standard errors in parentheses. $* * * \mathrm{p}<0.01 ; * * \mathrm{p}<0.05 ;{ }^{*} \mathrm{p}<0.10$. 


\section{CONCLUSIONS}

It appears that the PIECP is an effective program in terms of accomplishing its stated objectives. The first goal - inmate production that contributes to society - offsets incarceration costs, compensates crime victims and supports inmate families, is occurring through the generation and distribution of $\$ 368.2$ million in gross wages since the program's inception. Indiana and Tennessee, the states examined here, have cumulative contributions to the program of $\$ 29.0$ million and $\$ 17.9$ million, respectively, which represents approximately $7.5 \%$ of the programs cumulative gross wages. The states' distribution of funds across victims programs, room and board, family support, taxes and mandatory savings are representative of the program's average distributions.

For this study, the program's second stated goal - success in the community once the inmate is released - is evaluated in terms if inmate recidivism. While it does ignore financial considerations, non-reincarceration - or a lack of recidivism - is used as a proxy for post-release success. The results over one-year, two-year, and three-year post-release time periods consistently indicate a significant reduction in the odds of recidivism for PIECP participants. Also, while other recidivism studies often fail to address endogeneity from unobserved characteristics, this paper adds controls to address this issue. Here, a two-stage least squares IV approach was utilized and tested to be more reliable than the standard logit model, adding support to the claim of program effectiveness. Further, the PIECP participants were examined relative to a working inmates sample over one-year, two-year, and three-year post release time periods and again consistently demonstrate a significant reduction in the odds of recidivism for PIECP participants. The three-year, all inmates, pooled sample IV specification suggests an $8.8 \%$ reduction in the odds of recidivism and the three-year, working inmates, pooled sample IV specification suggests a $7.2 \%$ reduction.

This paper continues to establish the benefits of the PIECP program, but additional insight would be useful. A larger, or national, study might be utilized to identify which programs are most effective. Also, an examination of which specific industries within the program are most effective would add depth by potentially identifying which skills are most beneficial. Further, a measure of training intensity examining the effect of time employed and amount of training in a PIECP program would contribute to the analysis.

\section{AUTHOR INFORMATION}

Jeffrey Hopper is an Assistant Professor of Business Administration and is the Director of the Business Administration Program at Transylvania University in Lexington, Kentucky. E-mail: jhopper@transy.edu

\section{REFERENCES}

1. Becker, G.S. (1968). Crime and Punishment: An Economic Approach. The Journal of Political Economy, 76(2) 169-217.

2. Chapman, S., Grealish, B., Grassel, K., Viscuso, B. \& Lam, L. (2010). California Department of Corrections and Rehabilitation: 2010 Adult Institutions Outcome Evaluation Report. CDCR Office of Research. Retrieved from: http://www.cdcr.ca.gov

3. Ehrlich, I. (1996). Crime, Punishment, and the Market for Offenses. The Journal of Economic Perspectives, 10(1) 43-67.

4. Gould, E., Weinberg B. \& Mustard, D. (2002). Crime rates and local labor market opportunities in the United States: 1979-1997. Review of Economics and Statistics, 84(1) 45-61.

5. Heckman, J. \& Polachek, S. (1974). Empirical Evidence of the Functional Form of the Earnings-School relationship. Journal of the American Statistical Association, 69(346) 350-364.

6. Indiana Department of Corrections. (2012). Adult Facilities Guidelines. Retrieved from: http://www.in.gov/idoc/2332.htm

7. International Centre for Prison Studies. (2009). World Prison Population List $8^{\text {th }}$ edition. Kings College, London.

8. Levitt, S. D. (1999). Preliminary Opinion on the Economics of Inmate Labor Participation. The Economics of Inmate Labor Force Participation.

9. Liptak, A. (2008, April 23). U.S. prison population dwarfs that of other nations. The New York Times. 
10. Lochner, L. (2004). Education, Work, and Crime: Theory and Evidence. International Economic Review, 45(3) $811-843$.

11. National Correctional Industries Association. (2013) Third Quarter 2012 Cumulative Data Report. Retrieved from: http://www.nationalcia.org/piecp-2/quarterly-statistical-reports

12. Petersik, T. (2003). Identifying Beneficiaries of PIE Inmate Incomes: Who Benefits from Wage Earnings of Inmates Working in the Prison Industry Enhancement (PIE) Program? Report of the Center for Economic Research, George Washington University and of the National Correctional Industries Association. Washington, D.C.

13. Pew Center on the States. (2011). State of Recidivism: The Revolving Door of America's Prisons. Washington, DC: The Pew Charitable Trusts.

14. Tennessee Department of Corrections. Division of Policy, Planning, \& Research. (2001). TDOC Release Trends and Failure Rates: Felon Releases 1993-1999. TDOC Recidivism Brief.

15. Tennessee Department of Corrections. (2011). Inmate Policies and Procedures. Retrieved from: http://www.tennessee.gov/correction/policies/poly.html

16. U.S. Department of Justice. Office of Justice Programs. Bureau of Justice Assistance. (2004). Prison Industry Enhancement Certification Program. Program Brief. Washington DC: NCJ 203483.

17. U.S. Department of Justice. Office of Justice Programs. Bureau of Justice Statistics. (1989). Recidivism of Prisoners Released in 1983. Special Report. Washington DC. NCJ 116261.

18. U.S. Department of Justice. Office of Justice Programs. Bureau of Justice Statistics. (2002). Recidivism of Prisoners Released in 1994. Special Report. Washington DC. NCJ 193427.

19. U.S. Department of Justice. Office of Justice Programs. Bureau of Justice Statistics. (2012a). Correctional Populations in the United States, 2011. Bulletin. Washington DC. NCJ 239972.

20. U.S. Department of Justice. Office of Justice Programs. Bureau of Justice Statistics. (2012b). State Correctional Expenditures, FY 1982-2010. Bulletin. Washington DC. NCJ 239672.

21. Weiman, D., Stoll, A. \& Bushway, S. (2007). Barriers to reentry?: The labor market for released prisoners in post-industrial America. New York: Russell Sage Foundation.

22. Wilson, D., Gallagher, C. \& MacKenzie, D. (2001). A Meta-Analysis of Corrections-Based Education, Vocation, and Work Programs for Adult Offenders. Journal of Research in Crime and Delinquency, 37(4) $347-368$. 


\section{NOTES}

